\title{
Antidiabetic and Antioxidant Properties of Copper Nanoparticles Synthesized by Medicinal Plant Dioscorea bulbifera
}

Sougata Ghosh ${ }^{1,2}$, Piyush More1, Rahul Nitnavare1, Soham Jagtap ${ }^{1}$, Rohan Chippalkatti' ${ }^{1}$, Abhishek Derle ${ }^{1}$, Rohini Kitture ${ }^{3}$, Adersh Asok ${ }^{4}$, Sangeeta Kale ${ }^{3}$, Shailza Singh ${ }^{5}$, Mahemud L Shaikh ${ }^{5}$, Boppana Ramanamurthy ${ }^{5}$, Jayesh Bellare ${ }^{6}$ and Balu A Chopade ${ }^{7 *}$

${ }^{1}$ Institute of Bioinformatics and Biotechnology, University of Pune, Pune-411007, India

${ }^{2}$ Department of Microbiology, Modern College of Arts, Science and Commerce, Ganeshkhind, Pune-411016, India

${ }^{3}$ Department of Applied Physics, Defense Institute of Advanced Technology, Girinagar, Pune-411025, India

${ }^{4}$ The Centre for Research in Nanotechnology and Science (CRNTS), Indian Institute of Technology Bombay, Powai, Mumbai 400076, India

${ }^{5}$ National Centre for Cell Science, University of Pune Campus, Ganeshkhind, Pune-411007, India

${ }^{6}$ Department of Chemical Engineering, Indian Institute of Technology, Bombay, Powai, Mumbai-400076, India

${ }^{7}$ Department of Microbiology, University of Pune, Pune-411007, India

\begin{abstract}
Background: Biological route for synthesis of copper nanoparticles (CuNPs) with therapeutic potential is a major challenge. In this study, CuNPs were synthesized by D. bulbifera tuber extract (DBTE) which were further evaluated for antidiabetic and free radical scavenging activity.

Methods: CuNPs synthesized by DBTE were characterized by UV-visible spectroscopy, transmission electron microscopy, energy dispersive spectroscopy and dynamic light scattering. CuNPs were checked for a-amylase and $\alpha$-glucosidase inhibition along with interaction studies employing fluroscence spectroscopy, circular dichroism spectroscopy and computational docking. DPPH, nitric oxide and superoxide radical scavenging activities of CuNPs were also checked.

Results: Spherical monodispersed CuNPs were synthesized within $5 \mathrm{~h}$ that was indicated by a colour change from pale blue to brown. Majority of the nanoparticles synthesized were found to be between 12 to $16 \mathrm{~nm}$ as showed in DLS which grew till a final size of 86 to $126 \mathrm{~nm}$ as indicated in TEM. Bioreduced CuNPs showed $38.70 \pm 1.45 \%$ and 34.72 $\pm 1.22 \%$ inhibition against porcine and murine pancreatic amylase, respectively with an uncompetitive mode that was further confirmed by docking studies. Fluorescence spectroscopy confirmed the interaction of CuNPs to the enzyme via Trp residues while CD spectra indicated the structural and conformational changes on binding of CuNPs to the enzyme. CuNPs exhibited $99.09 \pm 0.15 \%$ inhibition against $\alpha$-glucosidase while $90.67 \pm 0.33 \%$ inhibition against murine intestinal glucosidase, respectively. CuNPs showed $40.81 \pm 1.44 \%, 79.06 \pm 1.02 \%$ and $48.39 \pm 1.46 \%$ scavenging activity against $\mathrm{DPPH}$, nitric oxide and superoxide radicals respectively.
\end{abstract}

Conclusion: D.bulbifera tuber extract mediated bioreduction is most rapid route to synthesize novel CuNPs with promising antidiabetic and antioxidant properties. This is the first detailed report which provides intense scientific rationale for the use of CuNPs as nanomedicine for efficient control of T2DM and oxidative stress.

Keywords: Dioscorea bulbifera; Copper nanoparticles; Type 2 diabetes mellitus (T2DM); Enzyme inhibition; Antioxidant

\section{Introduction}

Diabetes Mellitus (DM) is a pathological condition, associated with severe physiological imbalances. It is primarily an endocrine and metabolic disorder characterized by chronic hyperglycemia that produces multiple biochemical impairments and oxidative stress [1,2]. It is estimated that there are 143 million people in the world with diabetes and this number will probably double by the year 2030 [3]. Type 2 diabetes mellitus (T2DM), known as non-insulin-dependent diabetes mellitus (NIDDM) is a chronic metabolic disease which is characterized by post prandial hyperglycemia (PPHG). Although recently, wide varieties of synthetic drugs are being used for the treatment of T2DM, most of them possess pronounced side effects in the long run particularly, drug resistance, hepatotoxicity, abdominal pain, flatulence and diarrhea [4-6]. Therefore, there is a need for a search of an alternative agent possessing hypoglycemic effect on T2DM.

Attempts to identify alternative antidiabetic compounds have been reported where metal ions such as vanadium, zinc, manganese, copper, chromium, and tungsten exhibited in-vitro as well as invivo antidiabetic activity [7-13]. $\alpha$-glucosidase and $\alpha$-amylase are promising drug candidates in the treatment and prevention of T2DM as they are involved in sugar absorption [14]. Hereby an excellent inhibitor would limit the absorption of dietary carbohydrates and in turn suppress postprandial hyperglycemia. However, reports on the metal nanoparticles to show antidiabetic activity are rare and it needs attention. Scavenging of free radicals and inhibition of $\alpha$-amylase and a-glucosidase, are two important preventive measures of diabetes [1518]. Although there are reports on the relationship between metals and enzyme activity, only preliminary studies on relationship between metal nanoparticles and $\alpha$-glucosidase as well as $\alpha$-amylase action are reported [19]. Similarly there are no evidences on establishment of the mechanism for the antidiabetic activity by metal nanoparticles.

Copper, a transition metal, is one of the most frequently occurring elements integrated into essential biochemical pathways. There are

*Corresponding author: Balu A Chopade, Professor, Department of Microbiology University of Pune, Pune 411007, India, Tel: +91 020 25690643, Fax: +91 020 25690087; E-Mail: chopade@unipune.ac.in

Received August 25, 2015; Accepted September 22, 2015; Published September 30, 2015

Citation: Ghosh S, More P, Nitnavare R, Jagtap S, Chippalkatti R, et al. (2015) Antidiabetic and Antioxidant Properties of Copper Nanoparticles Synthesized by Medicinal Plant Dioscorea bulbifera. J Nanomed Nanotechnol S6: 007. doi:10.4172/2157-7439.S6-007

Copyright: (C) 2015 Ghosh S, et al. This is an open-access article distributed under the terms of the Creative Commons Attribution License, which permits unrestricted use, distribution, and reproduction in any medium, provided the original author and source are credited. 
number of biologically important molecules showing the catalytic activity or transfer processes, like oxygen transfer, and incorporating transition metals into their active sites [20]. Thus, copper nanoparticles (CuNPs) being more biocompatible, eliminates the risk for toxicity which is a major drawback for other metal nanoparticles with medicinal importance. Thus, biologically synthesized metal nanoparticles exhibiting diverse therapeutic potential are gaining more importance recently [21-27].

In view of the above background, synthesis of CuNPs employing medicinal plant can prove to be an efficient strategy in management of PPHG in T2DM as copper is known to inhibit $\alpha$-amylase activity $[28,29]$. Amylase inhibition has gastrointestinal and metabolic effects that may aid not only in the treatment of diabetes but also to obesity [30]. Diabetes is a major risk factor for premature atherosclerosis and oxidative stress plays an important role since diabetic monocytes produce increased superoxide anion $\left(\mathrm{O}_{2}^{-}\right)$[31]. Medicinal plant mediated synthesis of nanoparticles on the other hand render biocompatibility and provides a rapid and environmentally benign route of synthesis $[32,33]$. Hereby we chose D. bulbifera which has a potent antidiabetic activity apart from other medicinal significances such as, antimicrobial, antihyperlipidemic, antitumor and antiinflammatory properties [34-36]. Recently we have reported synthesis of silver and gold nanoparticles with excellent biological applications using D. bulbifera $[37,38]$.

In view of the above background, it is of immense importance to investigate the synthesis of copper nanoparticles (CuNPs) by $D$. bulbifera and check its antidiabetic properties. Earlier studies have showed electronic and optical property related chemical, biochemical and catalytic applications of CuNPs [39-42]. However, a systematic study on CuNPs against $\alpha$-amylase and $\alpha$-glucosidase towards the exploration of its antidiabetic potential followed by evaluation of the mode of inhibition is missing till date. Similarly, there are no antioxidant studies available supported by the mechanism of action. In this communication, we have studied the inhibitory potential of biogenic CuNPs against both $\alpha$-amylase and $\alpha$-glucosidase followed by study of enzyme inhibitor kinetics, ligand binding dynamics supported by in silico docking studies to reveal the mode of CuNPs' inhibitory action in addition to antioxidant activities.

\section{Materials and Methods}

\section{Plant material and preparation of extract}

D. bulbifera tubers were collected from natural geographical landscapes of Nashik region, Western Ghats of Maharashtra, India, and were identified and authenticated by botanist from National Research Institute of Basic Ayurvedic Sciences, Central Council for Research in Ayurveda and Siddha, Department of Ayush, Ministry of Health and Family Welfare, Government of India, New Delhi, Nehru Garden, Kothrud, Pune, India assigning voucher specimen number 860 [36]. D. bulbifera tuber extract was prepared as described in our previous report [38]. In short, thoroughly washed tubers were sliced into small pieces and shade dried for 3 days followed by blending into fine powder. $5 \mathrm{~g}$ of finely ground tuber powder was boiled with $100 \mathrm{~mL}$ of sterile distilled water for $5 \mathrm{~min}$ in a $300 \mathrm{~mL}$ Erlenmeyer flask. The extract obtained was filtered through Whatman filter paper No.1. The filtrate was collected and stored at $4^{\circ} \mathrm{C}$.

\section{Synthesis and characterization of copper nanoparticles}

$5 \mathrm{ml}$ of DBTE was added to $95 \mathrm{ml}$ of $1 \mathrm{mM}$ aqueous $\mathrm{CuSO}_{4} \cdot 5 \mathrm{H}_{2} \mathrm{O}$ solution and kept under shaking condition at $150 \mathrm{rpm}$ in the dark at $40^{\circ} \mathrm{C}$. Reduction of $\mathrm{Cu}^{2+}$ ions was monitored by measuring the UVvis spectra of the solution at regular intervals on a spectrophotometer (SpectraMax M5, Molecular Devices Corporation, Sunnyvale, CA) operated at resolution of $1 \mathrm{~nm}$. Bioreduced CuNPs were structurally analyzed for the surface morphology and particle size employing transmission electron microscopy (Tecnai 12 cryo TEM, FEI, Netherland). Elemental analysis was carried out in the energy dispersive spectrometer (EDS) equipped in JEOL JSM 6360A analytical scanning electron microscope at an energy range $0-20 \mathrm{keV}$. The diffraction data for the dry CuNPs powder were recorded on a Brucker $\mathrm{x}$-ray diffractometer using a $\mathrm{Cu} \mathrm{Ka}(1.54 \AA)$ source. Phase formation was confirmed from characteristic peaks such as (111), (200) and (220). Particle size analysis was carried out using the dynamic light scattering (Zetasizer Nano-2590, Malvern Instruments Ltd, Worcestershire, UK) in polysterene cuvette.

\section{Glycosidase inhibitory activity}

Porcine pancreatic amylase inhibition assay: Amylase activity was assayed using chromogenic 3,5-dinitrosalicylic acid (DNSA) as reported earlier [43]. CuNPs $(10 \mu \mathrm{g} / \mathrm{ml})$ was incubated with $50 \mu \mathrm{g} \mathrm{ml}^{-1}$ of porcine pancreatic $\alpha$-amylase at $37^{\circ} \mathrm{C}$ for $10 \mathrm{~min}$ [44]. One percent starch was used as substrate. $\alpha$-amylase without CuNPs was used as control. Reducing sugar was estimated using DNSA assay at A $540 \mathrm{~nm}$ and the inhibitory activity was calculated by using the formula:

$$
\% \text { Inhibition }=\left(\mathrm{A}^{2} 40_{\text {Control }}-\mathrm{A} 540_{\text {Test }}\right) / \mathrm{A}^{2} 40_{\text {Control }} \times 100
$$

The mode of inhibition of PPA by CuNPs was determined by using Michaelis-Menten and Lineweaver-Burk equations. Starch (1-5 mg $\mathrm{ml}^{-1}$ ) was incubated with CuNPs and PPA for $10 \mathrm{~min}$ and the residual enzyme activity was determined by DNSA.

Fluorescence spectrometry: Fluorescence measurements of porcine pancreatic $\alpha$-amylase were carried out in presence and in absence of CuNPs and were acquired using HORIBA JobinYvonFluorolog 3 model at $37^{\circ} \mathrm{C}$ with a $1.0 \mathrm{~cm}$ path length quartz cuvette in $0.02 \mathrm{M}$ sodium phosphate buffer ( $\mathrm{pH} 6.9$, containing $6 \mathrm{mM} \mathrm{NaCl}$ ). Both excitation and emission slits were set at $3.0 \mathrm{~nm}$. The samples were excited at $270 \mathrm{~nm}$, and the emission spectra were recorded from 280 to $450 \mathrm{~nm}$. Concentration of CuNPs and enzyme used were same as above.

Circular dichroism (CD) spectrometry: Structural changes in PPA in presence of CuNPs was checked by recording CD spectra at $37^{\circ} \mathrm{C}$ on a Jasco-J-815 spectropolarimeter at a scan speed of $40 \mathrm{~nm} /$ min with a response time of $1 \mathrm{~s}$ and a slit width of $1 \mathrm{~nm}$. Quartz cell of $2 \mathrm{~mm}$ path length was used for the measurements in 190-300 nm range. All measurements were made at a fixed enzyme vs CuNPs concentration mentioned above in phosphate buffered saline. Each spectrum reported is an average of three successive scans.

Molecular docking: All the docking calculations were performed by using Autodock 4.2 Tools. The model was first modified by adding all hydrogens and removal of water molecules using builder module of Autodock. Macromolecule was kept rigid, while all torsional bonds of ligands were set free to rotate. The docking results from each of the 165 calculations were clustered on the basis of RMSD between the cartesian coordinates of the ligand atoms and were ranked according to the free energy of binding. The structure with lowest free energy of binding in a highly populated cluster was chosen as the optimal docking pose. Because the system is required to be neutral for calculations, charges were balanced with sufficient amount of sodium counter ions. A cubic box was chosen, with periodic boundary conditions. The force field parameters of ligand were obtained from PRODRG web server. At 
first the system was energy minimized using steepest descent method. After energy minimization process, position restraint procedure was performed in association with NVT and NPT ensembles. An NVT ensemble was adopted at constant temperature of $300 \mathrm{~K}$ with time duration of 100 ps. After stabilization of temperature an isothermalisobaric ensemble (NPT) was performed. In this phase a constant pressure of 1.0 bar was employed with time duration of 100 ps. NPT ensemble was finished after pressure stabilization. The Particle-Mesh Ewald (PME) method was used to treat the long-range electrostatic interaction and the cut-off method was used to treat the van der Waals interactions, with the cut-off distance of $1.0 \mathrm{~nm}$ [45-49].

Murine pancreatic and intestinal $\alpha$-amylase inhibition assay: Crude murine enzymes were used from 10 -week-old Swiss male mice weighing $20 \mathrm{gm}$. Entire procedure was carried out with guidelines of Institutional Animal Ethical Committee. The mouse was starved for 12 h. Pancreas and small intestine tissues were excised and homogenized with $10 \mathrm{mM}$ ice cold phosphate buffer containing $6 \mathrm{mM} \mathrm{NaCl}(1: 10$ dilution; w/v) and appropriate amount of protease inhibitors. Tissue homogenates were centrifuged for $10 \mathrm{~min}$ at 10,000 r.p.m. and the supernatant was taken as a source of enzyme that was diluted so as to get an absorbance of 0.4 (at $280 \mathrm{~nm}$ ) [2]. Enzyme inhibition assay was carried out as described above. Percentage inhibition of the samples against pancreatic $\alpha$-amylase and small intestinal $\alpha$-amylase were calculated.

a-glucosidase inhibitory assays: Glucosidase inhibition assay of CuNPs were carried out as per Ghosh et al.[2]. $100 \mu \mathrm{l}$ of $\alpha$-glucosidase $(0.1$ unit $/ \mathrm{ml})$ was mixed with $200 \mu \mathrm{l}$ of CuNPs $(100 \mu \mathrm{g} / \mathrm{mL})$ and incubated for $1 \mathrm{~h}$ at $37^{\circ} \mathrm{C}$. Initiation of enzyme action was carried out by addition of $10 \mathrm{mM} p$-nitrophenyl- $\alpha$-D-glucopyranoside in $100 \mathrm{mM}$ phosphate buffer of $\mathrm{pH} 6.8$ and stopped by adding $2 \mathrm{ml}$ of $0.1 \mathrm{M} \mathrm{Na}_{2} \mathrm{CO}_{3}$ after an incubation of $10 \mathrm{~min}$ at $37^{\circ} \mathrm{C}$. $\alpha$-Glucosidase activity was determined by measuring absorbance of the $p$-nitrophenol released from $p$ NPG at $420 \mathrm{~nm}$ using 96-well plate reader (SpectraMax M5, Molecular Devices Corporation, Sunnyvale, CA). One unit of glucosidase activity is defined as the amount of enzyme that hydrolyzed $1 \mu \mathrm{M}$ of $p$-nitrophenyl pyranoside per minute under assay condition.

$\%$ Inhibition $=\left(\mathrm{A} 420_{\text {Control }}-\mathrm{A} 420_{\text {Test }}\right) / \mathrm{A} 420_{\text {Control }} \times 100$

Crude murine intestinal a-glucosidase inhibition assay: Intestinal extract of Swiss mice was prepared by the above mentioned process which was used as source of $\alpha$-glucosidase. Inhibitory activity against the crude murine intestinal $\alpha$-glucosidase was checked using $p$-nitrophenyl- $\alpha$-D-glucopyranoside as substrate as per the above protocol.

Free radical scavenging assays: $\mathrm{DPPH}$ radical scavenging activity was carried out by addition of $20 \mu \mathrm{l}$ of CuNPs $(100 \mu \mathrm{g} / \mathrm{ml})$ to $80 \mu \mathrm{l}$ of methanolic solution of 2,2- diphenyl-1-picrylhydrazyl (DPPH, 100 $\mu \mathrm{M})$ in 96 well plate followed by incubation for $20 \mathrm{~min}$ in darkness at room temperature [50]. Change in absorbance was measured at $517 \mathrm{~nm}$ in a 96-well plate reader (SpectraMax M5, Molecular Devices Corporation, Sunnyvale, CA). Superoxide anion scavenging assay was carried out by photoactivated riboflavin method as reported earlier [51]. Nitric oxide scavenging activity of CuNPs was checked as per the report of Marcocci et al. Nitric oxide scavenging activity of CuNPs was checked as per the report of Marcocci et al. [52,53].

Electron spin resonance measurements: DPPH radical scavenging activity of CuNPs was measured using previously described method [54]. An ethanolic solution of $200 \mu \mathrm{l}$ of CuNPs $(100 \mu \mathrm{g})$ was added to $800 \mu \mathrm{l}$ of DPPH $(100 \mu \mathrm{M})$ in ethanol solution. The solutions were then transferred into a quartz capillary tube and fitted into the cavity of the electron spin resonance (ESR) spectrometer, after vigorous mixing for $10 \mathrm{~s}$. The X-band $(9.44 \mathrm{GHz})$ ESR trace of the DPPH'spin adduct was measured using JES - FA200 ESR spectrometer (JEOL, Tokyo, Japan) exactly $1 \mathrm{~min}$ later at $25^{\circ} \mathrm{C}$. Measurement conditions: central field $3475 \mathrm{G}$, modulation frequency $100 \mathrm{kHz}$, modulation amplitude $2 \mathrm{G}$, microwave power $5 \mathrm{~mW}$, gain $6.3 \times 10^{5}$ and sweep time of $2 \mathrm{~min}$.

\section{Results}

\section{UV-visible spectroscopy}

UV-visible spectroscopy is widely used for examining the size and shape controlled synthesis of metal nanoparticles in aqueous suspensions. Initially the color of the salt solution was pale blue which on addition of DBTE gradually changed to colorless and then to light brown and finally to intense brown which confirmed the synthesis of CuNPs (Figure 1). Absorption bands in the ultra violet-visible range is exhibited by colloidal dispersion of metal due to the excitation of plasmon resonance or interband transition which are characteristic property of the metallic nature of the particle. The corresponding UV-vis absorption spectrum of bioreduced CuNPs demonstrated a featureless Mie scattering profile without the appearance of an apparent surface plasmon band. However, the intensity of the spectra increased with time till $5 \mathrm{~h}$ indicating the completion of the synthesis.

\section{TEM, EDS, XRD, DLS analysis}

Morphological analysis of the bioreduced CuNPs employing TEM revealed spherical shape of different sizes (Figure 2). Very small nanoparticles were observed along with larger ones. All the nanoparticles were found to be embedded in the biomass. Larger nanoparticles were lesser in number which were in a range between 86 and $126 \mathrm{~nm}$ (Figure 2c). Spot EDS profile confirmed the presence of elemental copper in the bioreduced nanoparticles (Figure 3a). The XRD pattern of CuNPs is shown in Figure $3 \mathrm{~b}$ exhibited peaks, which when compared with the standard data released by Joint Committee for Powder Diffraction Standard (JCPDS), matched with copper (card no $04-0784$ ). The peaks at $2 \theta$ values $\sim 43,50$ and 74 degree correspond to the copper crystallite planes (111), (200), (220) respectively. The CuNPs had FCC crystal structure. Moreover, no extra peaks were

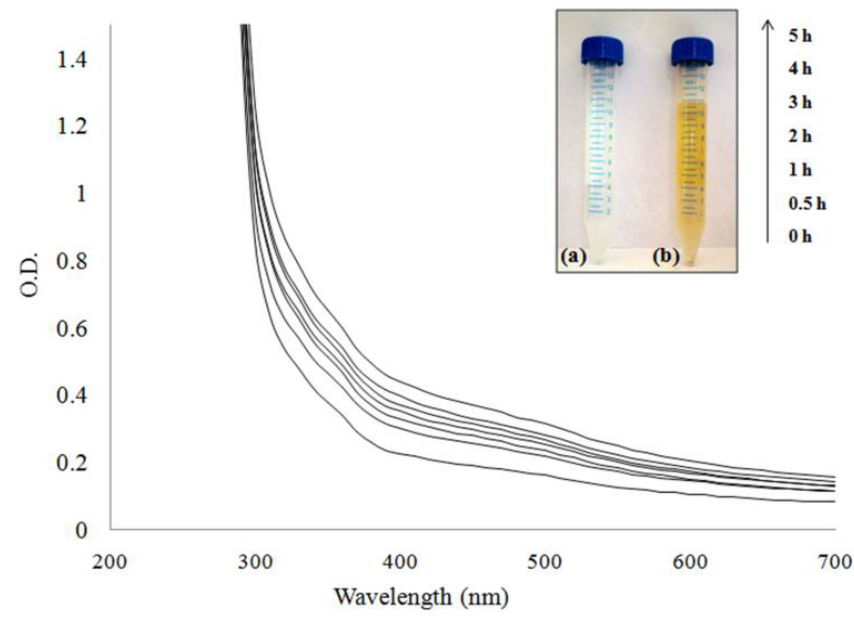

Figure 1: UV-visible spectra of CuNPs synthesized by DBTE. $5 \mathrm{~mL}$ of DBTE was added to $95 \mathrm{~mL}$ of $10^{-3} \mathrm{M}$ aqueous CuSO4.5H2O solution and kept under shaking condition at $150 \mathrm{rpm}$ in the dark at $40^{\circ} \mathrm{C}$. (a) Before bioreduction and (b) after bioreduction. 
Citation: Ghosh S, More P, Nitnavare R, Jagtap S, Chippalkatti R, et al. (2015) Antidiabetic and Antioxidant Properties of Copper Nanoparticles Synthesized by Medicinal Plant Dioscorea bulbifera. J Nanomed Nanotechnol S6: 007. doi:10.4172/2157-7439.S6-007

Page 4 of 9

found in the data. This rules out the possibility of attachment of any trace of biological material from DBTE onto the surface of CuNPs. Particle size distribution employing dynamic light scattering exhibited the presence of particles in a range from $8 \mathrm{~nm}$ to $220 \mathrm{~nm}$, majority being 12 to $16 \mathrm{~nm}$ (Figure 4). Bigger size might be due to capping of CuNPs by biomass which remained strongly associated in the close proximity of the nanoparticles.

\section{a-amylase inhibition assay}

CuNPs were found to inhibit pancreatic a-amylase more selectively (Figure 5). Maximum inhibition was exhibited against porcine pancreatic $\alpha$-amylase upto $38.70 \pm 1.45 \%$. DBTE synthesized CuNPs were found to be similarly potent as well against crude murine pancreatic amylase showing $34.72 \pm 1.22 \%$. However, acarbose showed a higher activity against amylase that was between 83 to $88 \%$. Crude murine intestinal amylase was inhibited till $18.04 \pm 0.82 \%$. The effect of CuNPs on kinetics of PPA catalyzed hydrolysis of starch was studied using the double reciprocal Lineweaver-Burk plots (Figure 6). Kinetic
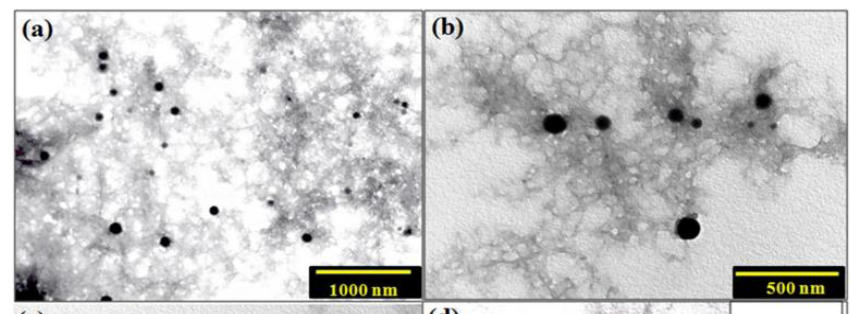

(c)
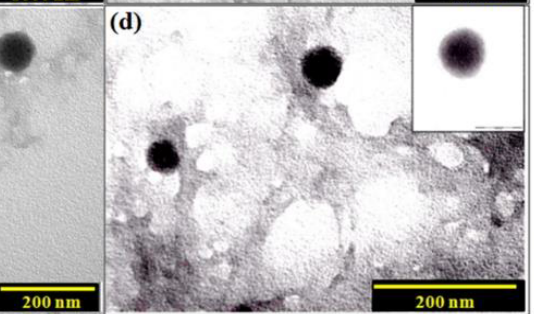

Figure 2: Transmission electron micrographs of the bioreduced CuNPs at different magnifications. (a) Monodispersed spherical nanoparticles with inset bar equivalent to $1000 \mathrm{~nm}$, (b)Isolated nano spheres with inset bar equivalent to $500 \mathrm{~nm}$, (c) and (d) Nanoparticles ranging from 80 to $130 \mathrm{~nm}$ with inset bar equivalent to $200 \mathrm{~nm}$. study revealed a decrease in both apparent $\mathrm{Km}$ and $\mathrm{Vmax}$ values in case of the enzyme activity of PPA in presence of CuNPs. The uninhibited enzyme substrate kinetic analysis showed a $\mathrm{Km}$ value of $13.38 \mathrm{mg}$ while a Vmax of $1.17 \mu \mathrm{M} / \mathrm{min}$. However, in presence of CuNPs the Km value decreased to 5.98 and $\mathrm{Vmax}$ decreased to $0.61 \mu \mathrm{M} / \mathrm{min}$. Thus, the mode of inhibition of PPA by CuNPs being uncompetitive for starch is novel (Table 1).

\section{Fluorescence studies}

A strong intrinsic UV A fluorescence from $\alpha$-amylase is attributed to the presence of Trp residue at various domains like catalytic site and calcium binding site of the enzyme (Figure 7). Thus quenching of intrinsic UV A fluorescence signifies direct interaction of CuNPs with $\operatorname{Trp}$ residues present in $\alpha$-amylase domains. Figure 7 shows decay in the fluorescence intensity of $a$-amylase in the presence of CuNPs at different time interval. This quenching of Trp fluorescence can be associated with the dynamic interaction of CuNPs with a-amylase via Trp residues which might be the underlying principle of enzyme inhibition mechanism exhibited by CuNPs.

\section{Circular dichroism studies}

Circular dichroism (CD) studies revealed the nature of interaction of $\alpha$-amylase with CuNPs (Figure 8). CD spectroscopy gave detailed information about the secondary structure of enzyme in presence and in absence of CuNPs. Two peaks minima of $\alpha$-amylase at 208 and 222 $\mathrm{nm}$, are attributed to a high $\alpha$-helical content of enzyme. Any alteration in the conformational changes of $a$-amylase can be reflected in CD spectra, either as a blue shift or diminished minimum. A diminish in negative humped peaks at $208 \mathrm{~nm}$ and $222 \mathrm{~nm}$ in presence of CuNPs was observed when compared with the control enzyme (Figure 8). This clearly indicated a probable interaction of CuNPs with the a-helix of enzyme, resulting in conformational change in secondary structure of the enzyme. This observation along with enzyme inhibition assay studies suggest a possible binding interaction of CuNPs with $\alpha$-amylase.

\section{a-glucosidase inhibition assays}

CuNPs exhibited extremely potent inhibitory activity against both pure $\alpha$-glucosidase as well as crude murine intestinal glucosidase (Figure 9). CuNPs showed $99.09 \pm 0.15 \%$ inhibition of $\alpha$-glucosidase while acarbose showed a slightly lower inhibition equivalent to $98.65 \pm$ $0.84 \%$. However, CuNPs $(90.67 \pm 0.33 \%)$ showed significantly superior
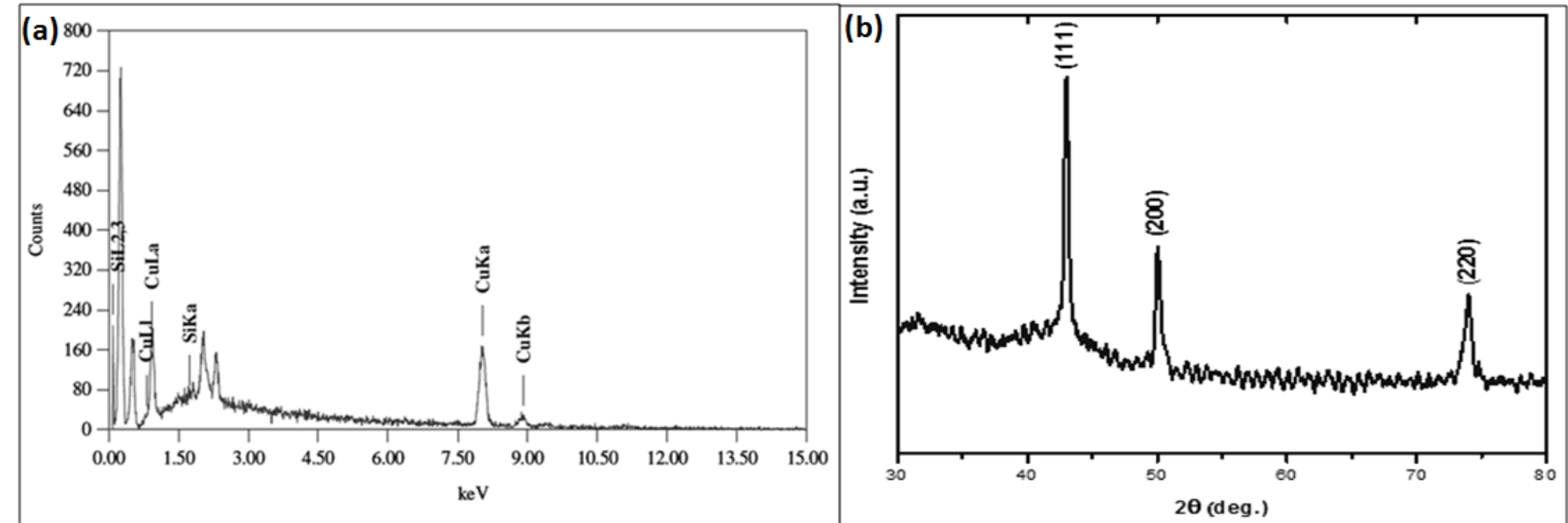

Figure 3: (a) Representative spot EDS profile of CUNPs synthesized by DBTE; (b) Representative x-ray diffraction profile of thin film CuNPs synthesized by DBTE. 
Citation: Ghosh S, More P, Nitnavare R, Jagtap S, Chippalkatti R, et al. (2015) Antidiabetic and Antioxidant Properties of Copper Nanoparticles Synthesized by Medicinal Plant Dioscorea bulbifera. J Nanomed Nanotechnol S6: 007. doi:10.4172/2157-7439.S6-007

Page 5 of 9

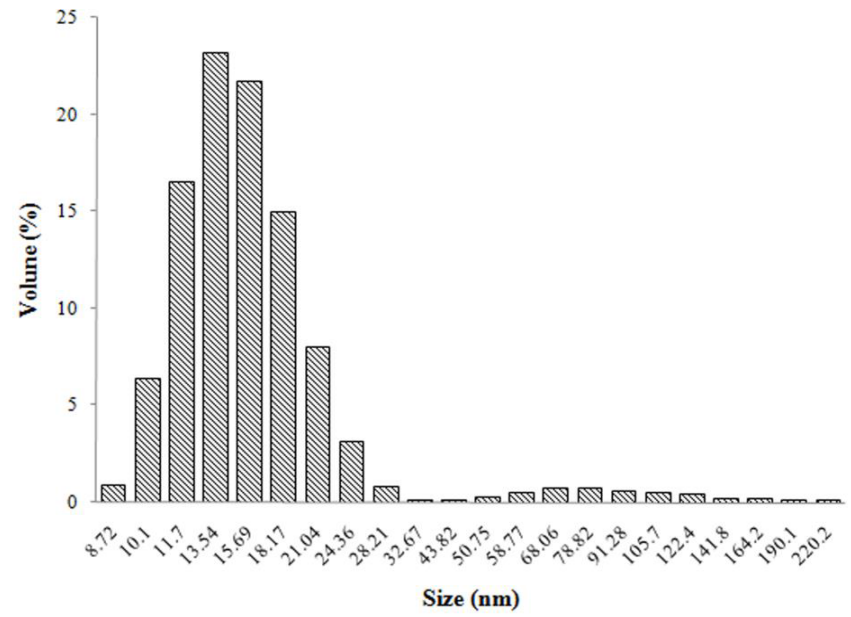

Figure 4: Particle size distribution of CuNPs synthesized by DBTE.

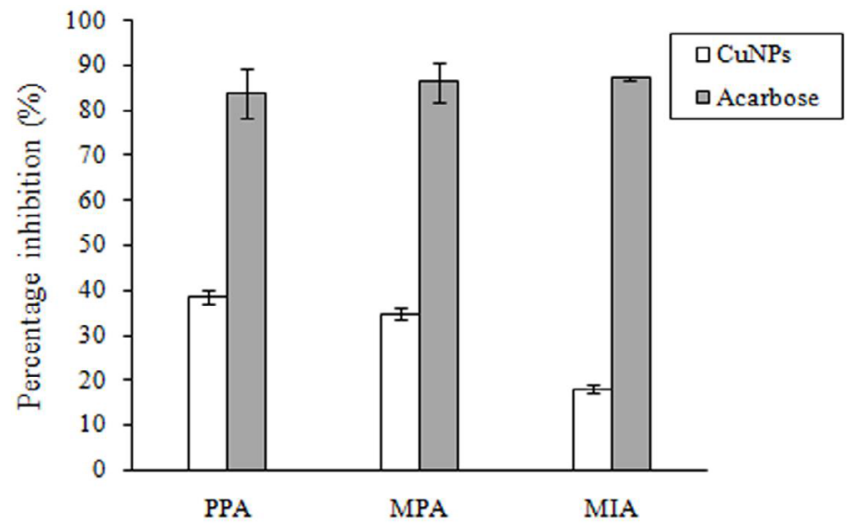

Figure 5: Inhibition of $\alpha$-amylase by CuNPs synthesized by DBTE. The data is indicated as the mean \pm SEM; $[n=3]$. PPA-porcine pancreatic $\alpha$-amylase; MPA-crude murine pancreatic amylase; MIA-crude murine intestinal amylase.

\begin{tabular}{|c|c|c|c|c|c|}
\hline Cluster & Sr No. & $\operatorname{Rmsd~} \mathbf{A}^{\circ}$ ) & $\mathbf{E}_{\text {inter (KCal·mol-1) }}$ & $\mathbf{E}_{\text {vdw (KCal-mol-1) }}$ & $\mathbf{E}_{\text {etr (KCal-mol-1) }}$ \\
\hline \multirow{2}{*}{ Cluster 1 } & 1 & $1.3 \pm 0.3$ & $-523 \pm 37$ & -39 & -487 \\
\cline { 2 - 6 } & 2 & $1.4 \pm 0.1$ & $-522 \pm 43$ & -45 & -488 \\
\hline \multirow{2}{*}{ Cluster 2 } & 1 & $1.2 \pm 0.3$ & $-317 \pm 36$ & -40 & -453 \\
\cline { 2 - 6 } & 2 & $1.3 \pm 0.1$ & $-542 \pm 47$ & -39 & -495 \\
\hline
\end{tabular}

Table 1: Statistical analysis of docking results for the different runs.

activity as compared to acarbose $(78.61 \pm 0.80 \%)$ in case of murine intestinal glucosidase.

\section{Docking studies}

Clusters are sorted according to average intermolecular energy. The non-bonded energies were calculated with the OPLS parameters. The electrostatic energy was calculated with an epsilon value of 1 . Copper is coordinated by two cysteines of a CxxC motif, expands its co-ordination sphere by binding an exogenous ligand. Copper tends to move from one loop to another and is consistent with the physiological direction of transfer, with concomitant structural rearrangements (Figure 10). The observed in silico data is in agreement with experimental observations.
The interaction is mainly of an electrostatic nature with hydrogen bonds stabilizing the complex.

\section{Free radical scavenging activity}

Bioreduced CuNPs showed $40.81 \pm 1.44 \%$ of $\mathrm{DPPH}$ radical scavenging activity which was slightly lower as compared to ascorbic acid (51.42 $\pm 1.78 \%)$ (Figure 11). However in case of both nitric oxide and superoxide CuNPs exhibited superior activity as compared to ascorbic acid. In case of nitric oxide CuNPs could scavenge upto 79.06 $\pm 1.02 \%$ that was significantly higher than that of ascorbic acid $(68.37$ $\pm 0.99 \%)$. Similarly, ascorbic acid showed $14.11 \pm 0.95 \%$ of superoxide scavenging activity while CuNPs showed an activity equivalent to 48.39 $\pm 1.46 \%$

\section{ESR study for antioxidant activity of CuNPs}

Bioreduced CuNPs were tested for free radical scavenging activity using standard DPPH assay by ESR spectroscopy. The ESR spectrum

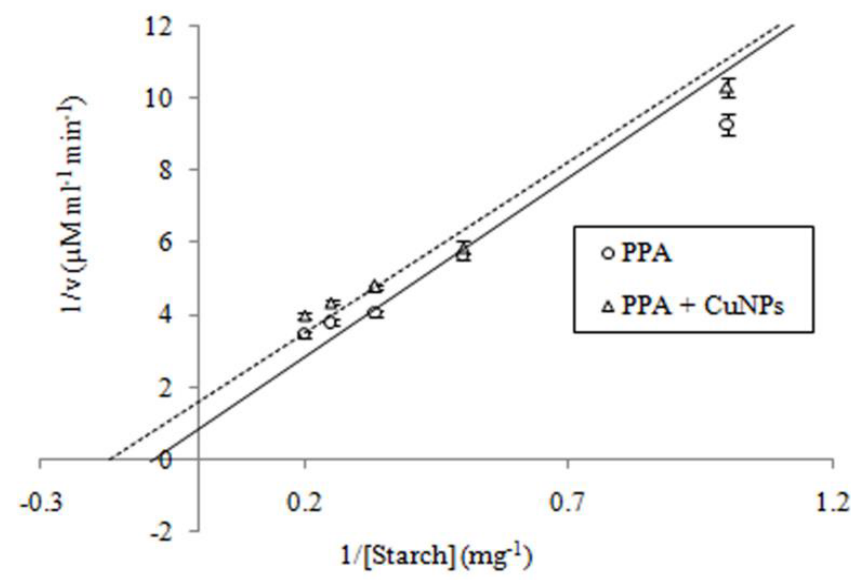

Figure 6: Lineweaver-Burk plot for PPA inhibition with CuNPs indicating an uncompetitive mode of inhibition with starch as substrate. The data is indicated as the mean \pm SEM; $[n=3]$.

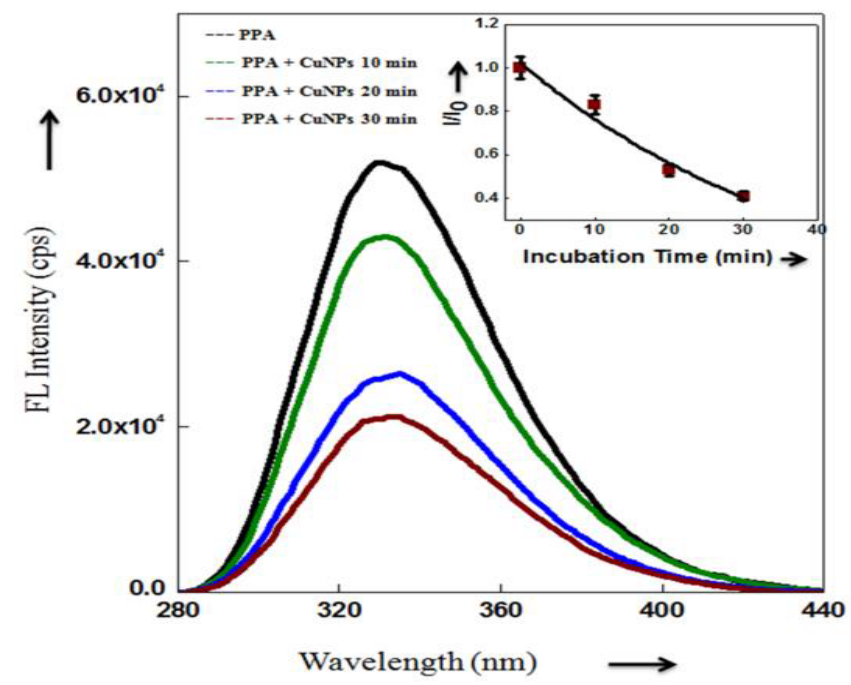

Figure 7: Fluorescence spectra showing the temporal decay of tryptophan fluorescence of PPA in the presence of CuNPs. Inset showing the first order exponential decay fit for $I / I_{0}$ vs Incubation time (where I is the intensity of Trp fluorescence with different time and $\mathrm{I}_{0}$ is the intensity PPA without CuNPs). 
Citation: Ghosh S, More P, Nitnavare R, Jagtap S, Chippalkatti R, et al. (2015) Antidiabetic and Antioxidant Properties of Copper Nanoparticles Synthesized by Medicinal Plant Dioscorea bulbifera. J Nanomed Nanotechnol S6: 007. doi:10.4172/2157-7439.S6-007

of DPPH radical taken at different incubation period in presence of CuNPs is shown in Figure 12. A gradual reduction in the integrated ESR signal intensity was observed with increase of duration of incubation,

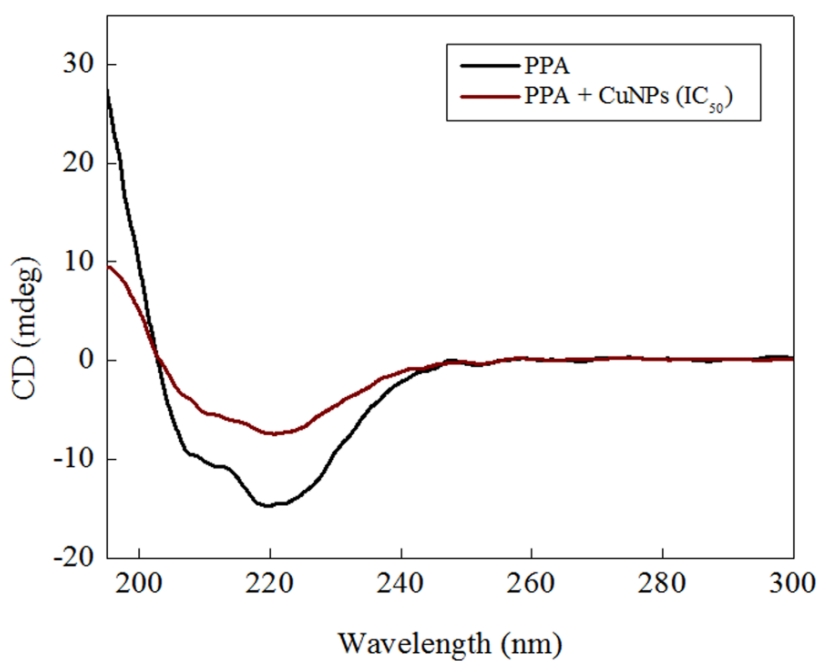

Figure 8: Circular dichroism spectra for PPA and PPA incubated with CuNPs

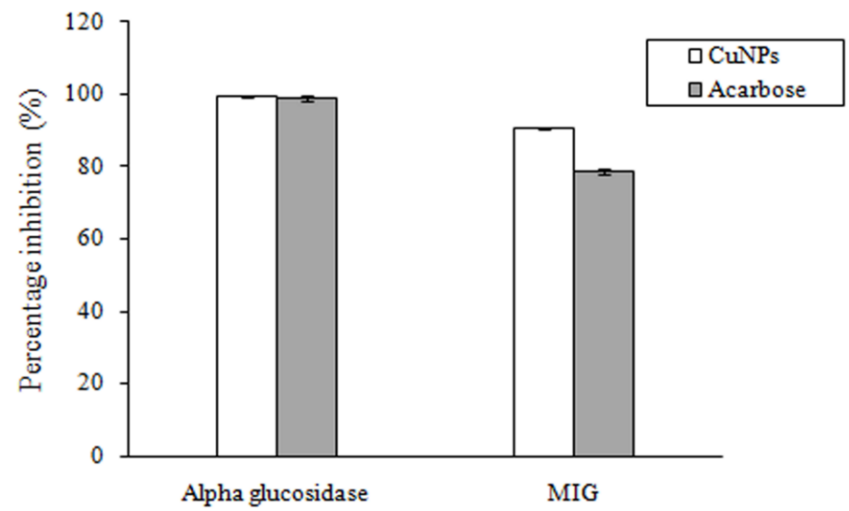

Figure 9: Inhibition of $\alpha$-glucosidase by CuNPs synthesized by DBTE. The data is indicated as the mean \pm SEM; $[n=3]$. MIG - crude murine intestinal glucosidase.
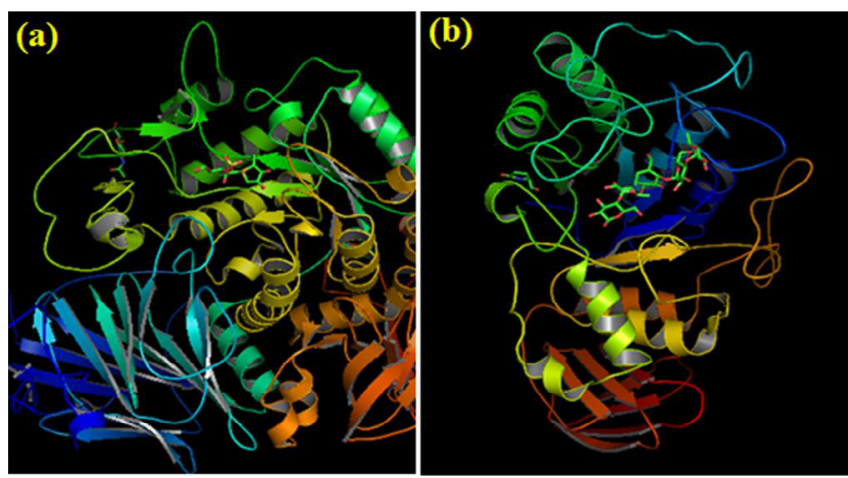

Figure 10: Interaction of CuNPs with PPA shown in different clusters sorted according to average intermolecular energy. (A) Cluster 1 and (B) Cluster 2 binding models.

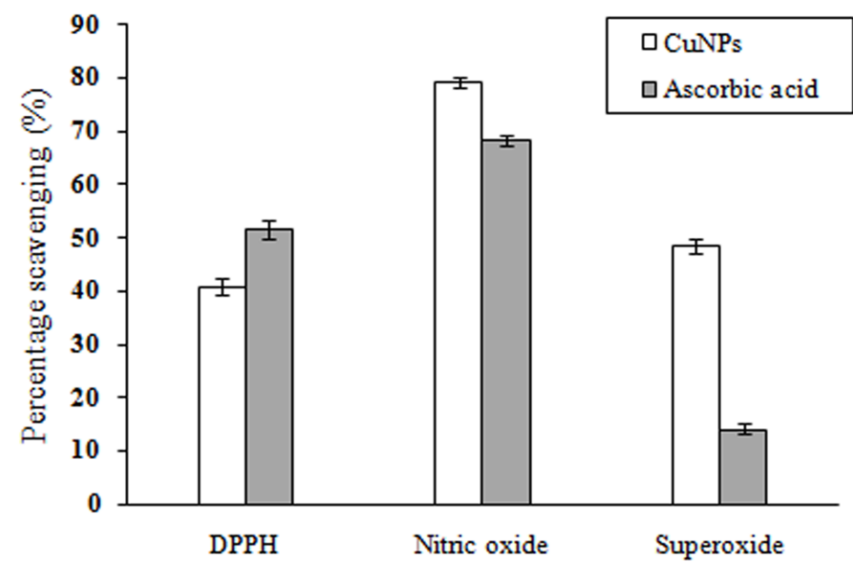

Figure 11: Scavenging of free radicals by CUNPs synthesized by DBTE. The data is indicated as the mean \pm SEM; $[n=3]$.

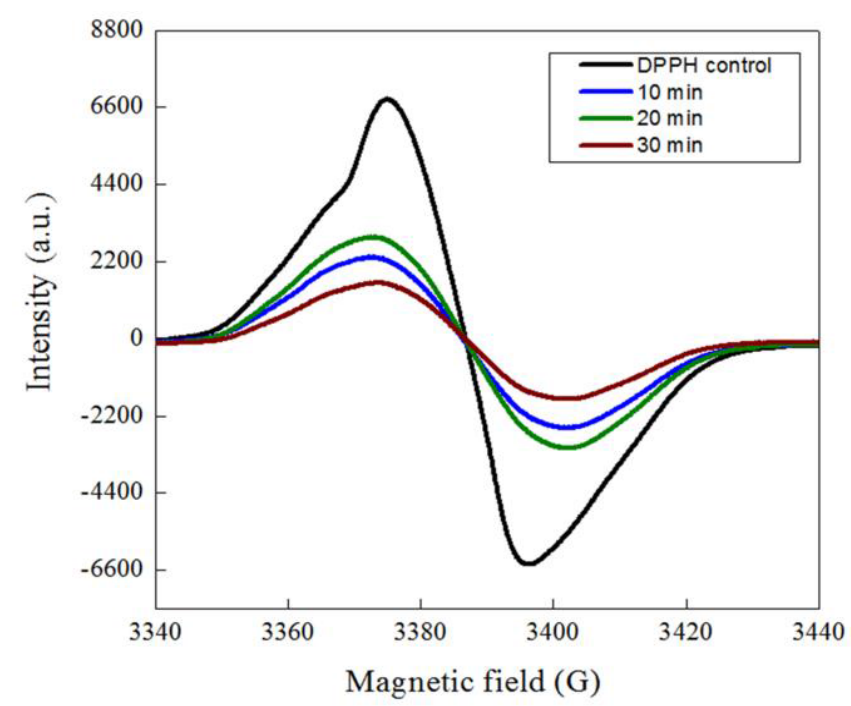

Figure 12: ESR spectra of DPPH radicals obtained in presence of CuNPs as a function of time.

which indicates that CuNPs are efficient scavenger of DPPH radicals.

\section{Discussion}

Although chemical methods are available for synthesis of CuNPs, there is a dearth of scientific literature on biogenic synthesis of CuNPs, particularly using medicinal plants. Hereby we report for the first time a novel rapid route for synthesis of CuNPs using D. bulbifera tuber extract. The synthesis completed within $5 \mathrm{~h}$ which is in accordance to our previous report on synthesis of AgNPs using D. bulbifera [38]. The bioreduced nanoparticles were monodispersed unlike the polydispersed CuNPs synthesized using latex of Calotropis procera L.[55]. Synthesis of CuNPs, indicated by development of reddish brown color was well in agreement with the previous report where CuNPs synthesis was associated with change of color from brownish red to dark reddish brown [40]. CuNPs are reported to typically exhibit a surface plasmon peak at around $560 \mathrm{~nm}$ [56]. However, corresponding UVvis absorption spectrum of freshly synthesized CuNPs demonstrated a featureless Mie scattering profile without appearance of an apparent surface plasmon band as reported reported previously [40,57-59]. 
Above observations might be attributed to smaller particle size [59].

We have reported high ascorbic acid content in DBTE which might be a probable reason for stabilization of smaller nanoparticles in addition to high intensity at around $330 \mathrm{~nm}$ attributed by oxidation product of ascorbic acid with simultaneous bioreduction of $\mathrm{Cu}^{2+}$ to CuNPs [37,57]. Metallic copper in spot EDS of bioreduced nanoparticles confirmed the synthesis of CuNPs [55,60]. Our results are in agreement with earlier reports where CuNPs synthesized by Magnolia kobus leaf extract showed spherical nanoparticles in a range between 50 to 250 $\mathrm{nm}$ [61]. Similarly, DBTE synthesized CuNPs were found in a range between 86 to $126 \mathrm{~nm}$. Smaller to larger nanoparticles with majority being 12 to $16 \mathrm{~nm}$ as shown in DLS studies indicates the gradual growth of smaller nanoparticles concurrent to the report on CuNPs formed by latex of Calotropis procera L. which were found in a size ranging from 5 to $30 \mathrm{~nm}$ average being $15 \pm 1.7 \mathrm{~nm}$ [55]. Similarly in case of CuNPs synthesized by Euphorbia nivulia, DLS studies showed that the average size of CuNPs were between 12 to $16 \mathrm{~nm}$ [60]. Recent reports on synthesis of CuNPs by Magnolia kobus, Ocimum sanctum leaf and Syzygium aromaticum extract highlight the probable role of some proteins and metabolites such as terpenoids and reducing sugars having functional groups of amines, alcohols, ketones, aldehydes, and carboxylic acids in reduction of copper ions and stabilization of synthesized CuNPs [62-64]. Thus, earlier reports on phytochemistry of D. bulifera tuber can clearly justify its potential for efficient synthesis and stabilization of CuNPs $[36,38]$.

Biogenic CuNPs inhibited both porcine pancreatic $\alpha$-amylase as well as crude murine pancreatic and intestinal amylase. Hereby for the first time we demonstrate the potential of CuNPs as antidiabetic agents. Recently, it was reported that elevated concentrations of $\mathrm{Cu}^{2+}$ ions lead to significant inhibition of the digestive enzyme, amylase while an increase in the activity of antioxidant enzymes namely, superoxide dismutase (SOD) and glutathione-S-transferase (GST) in giant freshwater prawn Macrobrachium rosenbergii. Binding interactions of CuNPs to PPA were confirmed by fluorescence and CD spectral changes indicating the alterations in the native conformation of the protein structure [65-67]. Further, the inhibition of a-glucosidase as well as murine intestinal glucosidase strongly support the therapeutic prospects of CuNPs as enzyme inhibitors with promising antidiabetic properties. $\mathrm{Cu}$ (II) ion and its complexes were reported to exhibit strong a-glucosidase inhibitory activity even greater than clinically used acarbose in in vitro studies [19,68-71].

DBTE synthesized CuNPs may function as chemopreventive agents for efficient management of PPHG. It has been reported that hyperglycemia associated to chronic diabetes generates reactive oxygen species (ROS) leading to oxidative stress which is a key player in lipid peroxidation and membrane damage [72]. Prevention of oxidative damage with free radical scavengers and inhibition of digestive enzymes such as $\alpha$-amylase and $\alpha$-glucosidase are two important therapeutic strategies for prevention of diabetes [73]. DBTE reduced CuNPs exhibited superior antioxidant activity, which indicated its contribution to protection against oxidative stress which is a key player in progression of diabetes and its related pathophysiological conditions. Although reports suggest that roasted copper "Tamra Bhasma" has a strong antioxidant potential leading to its hepatoprotective activity, there are no reports on CuNPs till date. Recently, pharmacological investigations have been reported on the use of 'tamra bhasma' for free radical scavenging activity [74-76]. Similarly, earlier reports suggest that CuNPs are responsible for wound healing due its biocompatibility as compared to copper salts [77]. Antioxidants along with balanced concentrations of microelements facilitate wound healing. At the same time, impairment of wound healing is reported in case of diabetes associated hyperglycemia as well as copper deficiency $[77,78]$. Thus, our study on free radical scavenging and $\alpha$-amylase and $\alpha$-glucosidase inhibition strongly rationalize and provides the scientific evidence on probable mechanism underlying the wound healing properties of CuNPs.

Hereby the results support the use of transition metal nanoparticles particularly, CuNPs as therapeutic agents towards the management of T2DM [78,79]. It provides considerable evidence on the antidiabetic promises of biogenic CuNPs, which can be potentially useful as preventive agents towards the initiation and development of freeradical induced diabetes mellitus and its complications [79].

\section{Conclusions}

Rapid synthesis of monodispersed spherical CuNPs was successfully accomplished by D. bulbifera tuber extract. This one step, eco-friendly efficient process involves plant based bio-resource serving as both reducing as well as stabilizing agents. We report here the excellent inhibitory potential of the CuNPs against $\alpha$-amylase and $\alpha$-glucosidase which are considered to be significant pharmacological targets for treatment of T2DM. Similarly, it exhibited superior antioxidant activity. This is the first ever report on the $\alpha$-amylase and $\alpha$-glucosidase inhibitory activity of CuNPs synthesized by DBTE. The high potency of these biogenic CuNPs for radical-scavenging and glycosidase inhibitory activities in vitro provided strong scientific evidence for antidiabetic potential of CuNPs which intensely rationalize its use in therapy and management of T2DM.

\section{Acknowledgements}

We are thankful to Prof. Ajit R. Kulkarni, Department of Metallurgical Engineering and Materials Science, Indian Institute of Technology Bombay Mumbai for fruitful discussion on PL and CD spectroscopy studies. S. Ghosh thanks Council of Scientific and Industrial Research (CSIR, Government of India) for Senior Research Fellowship (09/137(0516)/2012-EMR-I). We acknowledge financial support for UPE Phase II- Focus Area Biotechnology, for 2012-2017 awarded to University of Pune by UGC, New Delhi, India and Board of College and University Development (BCUD) by University of Pune.

\section{References}

1. Kumar RP, Sujatha D, Saleem TSM, Chetty CM, Ranganayakulu D (2010) Potential antidiabetic and antioxidant activities of Morus indica and Asystasia gangetica in alloxan induced diabetes mellitus. J Exp Pharmacol 2: 29-36.

2. Ghosh S, Ahire M, Patil S, Jabgunde A, Bhat Dusane M, et al. (2012) Antidiabetic Activity of Gnidia glauca and Dioscorea bulbifera: Potent Amylase and Glucosidase Inhibitors. Evid Based Complement Alternat Med 2012: 929051.

3. Boyle JP, Honeycutt AA, Narayan KM, Hoerger TJ, Geiss LS, et al. (2001) Projection of diabetes burden through 2050: impact of changing demography and disease prevalence in the U.S. Diabetes Care 24: 1936-1940.

4. Rao BK, Rao CH (2001) Hypoglycemic and antihyperglycemic activity of Syzygium alternifolium (Wt.) Walp. seed extracts in normal and diabetic rats. Phytomedicine 8: 88-93.

5. Fujisawa T, Ikegami H, Inoue K, Kawabata $\mathrm{Y}$, Ogihara T (2005) Effect of two alpha-glucosidase inhibitors, voglibose and acarbose, on postprandial hyperglycemia correlates with subjective abdominal symptoms. Metabolism 54: 387-390.

6. Singh SK, Rai PK, Jaiswal D, Watal G (2008) Evidence-based Critical Evaluation of Glycemic Potential of Cynodon dactylon. Evid Based Complement Alternat Med 5: 415-420.

7. Kitture R, Chordiya K, Gaware S, Ghosh S, More PA et al (2015) ZnO Nanoparticles-Red Sandalwood Conjugate: A Promising Anti-Diabetic Agent. J Nanosci Nanotechnol 15: 4046-4051. 
Citation: Ghosh S, More P, Nitnavare R, Jagtap S, Chippalkatti R, et al. (2015) Antidiabetic and Antioxidant Properties of Copper Nanoparticles Synthesized by Medicinal Plant Dioscorea bulbifera. J Nanomed Nanotechnol S6: 007. doi:10.4172/2157-7439.S6-007

8. Patil VS, Nandre KP, Ghosh S, Rao VJ, Chopade BA, et al. (2013) Synthesis, crystal structure and antidiabetic activity of substituted (E)-3-(Benzo [d]thiazol2-ylamino) phenylprop-2-en-1-one. Eur J Med Chem 59: 304-309.

9. Patil VS, Nandre KP, Ghosh S, Rao VJ, Chopade BA, et al. (2012) Synthesis and glycosidase inhibitory activity of novel (2-phenyl-4H-benzopyrimedo[2,1-b] thiazol-4-yliden)acetonitrile derivatives. Bioorg Med Chem Lett 22: 7011-7014.

10. Sakurai H, Kojima Y, Yoshikawa Y, Kawabe K, Yasui H (2002) Antidiabetic vanadium(IV) and zinc(II) complexes. Coord Chem Rev 226: 187-198.

11. Muñoz MC, Barberà A, Domínguez J, Fernàndez-Alvarez J, Gomis R, et al (2001) Effects of tungstate, a new potential oral antidiabetic agent, in Zucker diabetic fatty rats. Diabetes 50: 131-138.

12. Fonteles $M C$, Almeida MQ, Larner J (2000) Antihyperglycemic effects of 3-O-methyl-D-chiro-inositol and D-chiro-inositol associated with manganese in streptozotocin diabetic rats. Horm Metab Res 32: 129-132.

13. Coulston L, Dandona $P(1980)$ Insulin-like effect of zinc on adipocytes. Diabetes 29: $665-667$

14. Chiasson JL, Gomis R, Hanefeld M, Josse RG, Karasik A, et al. (1998) The STOP-NIDDM Trial: an international study on the efficacy of an alphaglucosidase inhibitor to prevent type 2 diabetes in a population with impaired glucose tolerance: rationale, design, and preliminary screening data. Study to Prevent Non-Insulin-Dependent Diabetes Mellitus. Diabetes Care 21: 17201725.

15. Patil AB, Ghosh S, Phadatare SD, Pathak P, Sharma GK, et al. (2015) Evaluation of malonic acid diamide analogues as radical scavenging agents. New J Chem 39: 1267-1273.

16. Parihar VS, Pawar NJ, Ghosh S, Chopade B, Kumbhar N, et al. (2015) Diazaspiro-iminosugars and polyhydroxylated spiro-bislactams: synthesis glycosidase inhibition and molecular docking studies. RSC Adv 5: 5290752915

17. Markad PR, Sonawane DP, Ghosh S, Chopade BA, Kumbhar N, et al. (2014) $\mathrm{y}$-Hydroxyethyl piperidine iminosugar and $\mathrm{N}$-alkylated derivatives: A study of their activity as glycosidase inhibitors and as immunosuppressive agents. Bioorg Med Chem 22: 5776-5782.

18. Siriwardena A, Sonawane DP, Bande OP, Markad PR, Yonekawa S, et al. (2014) Synthesis of 1,5-dideoxy-1,5-iminoribitol C-glycosides through a nitrone-olefin cycloaddition domino strategy: Identification of pharmacological chaperones of mutant human lysosomal?beta-galactosidase. J Org Chem 79: 4398-4404.

19. Wang Y, Ma L, Li Z, Du Z, Liu Z, et al. (2004) Synergetic inhibition of metal ions and genistein on alpha-glucosidase. FEBS Lett 576: 46-50.

20. Harris DI, Sass-Kortsak A (1967) The influence of amino acids on copper uptake by rat liver slices. J Clin Invest 46: 659-667.

21. Gaidhani SV, Yeshvekar RK, Shedbalkar UU, Bellare JH, Chopade BA (2014) Bio-reduction of hexachloroplatinic acid to platinum nanoparticles employing Acinetobacter calcoaceticus. Process Biochem 49: 2313-2319.

22. Shedbalkar U, Singh R, Wadhwani S, Gaidhani S, Chopade BA (2014) Microbial synthesis of gold nanoparticles: current status and future prospects. Adv Colloid Interface Sci 209: 40-48.

23. Singh R, Nawale LU, Arkile M, Shedbalkar UU, Wadhwani SA, et al. (2015) Chemical and biological metal nanoparticles as antimycobacterial agents: A comparative study. Int J Antimicrob Agents 46: 183-188.

24. Wadhwani SA, Shedbalkar UU, Singh R, Karve MS, Chopade BA (2014) Novel polyhedral gold nanoparticles: green synthesis, optimization and characterization by environmental isolate of Acinetobacter sp. SW30. World J Microbiol Biotechnol 30: 2723-2731.

25. Sant DG, Gujarathi TR, Harne SR, Ghosh S, Kitture R, et al. (2013) Adiantum philippense L. frond assisted rapid green synthesis of gold and silver nanoparticles. J Nanoparticles 1-9.

26. Gaidhani S, Singh R, Singh D, Patel U, Shevade K, et al. (2013) Biofilm disruption activity of silver nanoparticles synthesized by Acinetobacter calcoaceticus PUCM 1005. Mater Lett 108: 324-327.

27. Singh R, Wagh P, Wadhwani S, Gaidhani S, Kumbhar A, et al. (2013) Synthesis optimization, and characterization of silver nanoparticles from Acinetobacter calcoaceticus and their enhanced antibacterial activity when combined with antibiotics. Int J Nanomedicine 8: 4277-4290.
28. Asok A, Ghosh S, More PA, Chopade BA, Gandhi MN, et al. (2015) Surface defect rich $\mathrm{ZnO}$ quantum dots as antioxidants inhibiting a-amylase and a-glucosidase: a potential anti-diabetic nanomedicine. J Mater Chem B 3 : 4597-4606.

29. Li N, Zhao Y, Yang J (2008) Effects of water-borne copper on digestive and metabolic enzymes of the giant freshwater prawn Macrobrachium rosenbergii. Arch Environ Contam Toxicol 55: 86-93.

30. Layer P, Rizza RA, Zinsmeister AR, Carlson GL, DiMagno EP (1986) Effect of a purified amylase inhibitor on carbohydrate tolerance in normal subjects and patients with diabetes mellitus. Mayo Clin Proc 61: 442-447.

31. Venugopal SK, Devaraj S, Yang T, Jialal I (2002) Alpha-tocopherol decreases superoxide anion release in human monocytes under hyperglycemic conditions via inhibition of protein kinase C-alpha. Diabetes 51: 3049-3054.

32. Salunke GR, Ghosh S, Santosh Kumar RJ, Khade S, Vashisth P, et al. (2014) Rapid efficient synthesis and characterization of silver, gold, and bimetallic nanoparticles from the medicinal plant Plumbago zeylanica and their application in biofilm control. Int J Nanomedicine 9: 2635-2653.

33. Ghosh S, Patil S, Ahire M, Kitture R, Gurav DD, et al. (2012) Gnidia glauca flower extract mediated synthesis of gold nanoparticles and evaluation of its chemocatalytic potential. J Nanobiotechnology 10: 17.

34. Ghosh S, Parihar VS, More P, Dhavale DD, Chopade BA (2015) Phytochemistry and therapeutic potential of medicinal plant: Dioscorea bulbifera. Med Chem (Los Angeles) 5: 154-159.

35. Ghosh S, More P, Derle A, Patil AB, Markad P, et al. (2014) Diosgenin from Dioscorea bulbifera: novel hit for treatment of type II diabetes mellitus with inhibitory activity against ÎI-amylase and Ît-glucosidase. PLoS One 9: e106039.

36. Ghosh S, Derle A, Ahire M, More P, Jagtap S, et al. (2013) Phytochemica analysis and free radical scavenging activity of medicinal plants Gnidia glauca and Dioscorea bulbifera. PLoS One 8: e82529.

37. Ghosh S, Jagtap S, More P, Shete UJ, Maheshwari NO, et al. (2015) Dioscorea bulbifera Mediated Synthesis of Novel Au core Ag shell Nanoparticles with potent antibiofilm and antileishmanial activity. J Nanomater 1-12.

38. Ghosh S, Patil S, Ahire M, Kitture R, Kale S, et al. (2012) Synthesis of silver nanoparticles using Dioscorea bulbifera tuber extract and evaluation of its synergistic potential in combination with antimicrobial agents. Int $J$ Nanomedicine 7: 483-496.

39. Deng D, Jin Y, Cheng Y, Qi T, Xiao F (2013) Copper nanoparticles: aqueous phase synthesis and conductive films fabrication at low sintering temperature. ACS Appl Mater Interfaces 5: 3839-3846.

40. Cuya Huaman JL, Sato K, Kurita S, Matsumoto T, Jeyadevan B (2011) Copper nanoparticles synthesized by hydroxyl ion assisted alcohol reduction for conducting ink. J Mater Chem 21: 7062-7069.

41. Lee Y, Choi JR, Lee KJ, Stott NE, Kim D (2008) Large-scale synthesis of copper nanoparticles by chemically controlled reduction for applications of inkjet-printed electronics. Nanotechnology 19: 415604

42. Foresti E, Fracasso G, Lanzi M, Lesci IG, Paganin L, et al. (2008) New thiophene monolayer-protected copper nanoparticles: synthesis and chemicalphysical characterization. J Nanomater 649130.

43. Mane RS, Ghosh S, Singh S, Chopade BA, Dhavale DD (2011) Synthesis of anomeric 1,5-anhydrosugars as conformationally locked selective $\hat{I} \pm-$ mannosidase inhibitors. Bioorg Med Chem 19: 6720-6725.

44. Sanap SP, Ghosh S, Jabgunde AM, Pinjari RV, Gejji SP, et al. (2010) Synthesis, computational study and glycosidase inhibitory activity of polyhydroxylated conidine alkaloids-a bicyclic iminosugar. Org Biomol Chem 8: 3307-3315.

45. Trott O, Olson AJ (2010) AutoDock Vina: improving the speed and accuracy of docking with a new scoring function, efficient optimization, and multithreading. J Comput Chem 31: 455-461.

46. Morris GM, Goodsell DS, Halliday RS, Huey R, Hart WE, et al. (1998) Automated docking using a Lamarckian genetic algorithm and an empirical binding free energy function. J Comput Chem 19: 1639-1662.

47. Humphrey W, Dalke A, Schulten K (1996) VMD: visual molecular dynamics. J Mol Graph 14: 33-38, 27-8.

48. Berendsen HJC, van der Spoel D, van Drunen R (1995) GROMACS: A message-passing parallel molecular dynamics implementation. Comput Phys Commun 91: 43-56. 
Citation: Ghosh S, More P, Nitnavare R, Jagtap S, Chippalkatti R, et al. (2015) Antidiabetic and Antioxidant Properties of Copper Nanoparticles Synthesized by Medicinal Plant Dioscorea bulbifera. J Nanomed Nanotechnol S6: 007. doi:10.4172/2157-7439.S6-007

49. Darden T, York D, Pedersen L (1993) Particle mesh Ewald: An $N \log (N)$ method for Ewald sums in large systems. J Chem Phys 98: 10089.

50. Rahman MAA, Moon SS (2007) Antioxidant polyphenol glycosides from the plant Draba nemorosa. Bull Korean Chem Soc 28: 827-831.

51. Kitture R, Ghosh S, Kulkarni P, Liu XL, Maity D, et al. (2012) Fe3O4-citratecurcumin: Promising conjugates for superoxide scavenging, tumor suppression and cancer hyperthermia. J Appl Phys 111: 064702.

52. Marcocci L, Packer L, Droy-Lefaix MT, Sekaki A, Gardès-Albert M (1994) Antioxidant action of Ginkgo biloba extract EGb 761. Methods Enzymol 234: $462-475$.

53. Tan M, Liu Y, Luo X, Chen Z, Liang H (2011) Antioxidant Activities of Plumbagin and Its Cu (II) Complex. Bioinorg Chem Appl 2011: 898726.

54. Pakhale SS, Karibasappa GS, Ramchandani AG, Bhushan B, Sharma A (2007) Scavenging effect of Indian grape polyphenols on 2,2'-diphenyl-1picrylhydrazyl(DPPH) radical by electron spin resonance spectrometry. Indian J Exp Biol 45: 968-973.

55. Harne S, Sharma A, Dhaygude M, Joglekar S, Kodam K, et al. (2012) Novel route for rapid biosynthesis of copper nanoparticles using aqueous extract of Calotropis procera L. latex and their cytotoxicity on tumor cells. Colloids Surfaces B Biointerfaces 95: 284-288.

56. Creighton JA, Eadon DG (1991) Ultraviolet visible absorption spectra of the colloidal metallic elements. J Chem Soc Faraday Trans 87: 3881-3891.

57. Xiong J, Wang $Y$, Xue Q, Wu X (2011) Synthesis of highly stable dispersions of nanosized copper particles using l-ascorbic acid. Green Chem 13: 900-904.

58. Samim M, Kaushik NK, Maitra A (2007) Effect of size of copper nanoparticles on its catalytic behaviour in Ullmann reaction. Bull Mater Sci 30: 535-540.

59. Chen S, Sommers JM (2001) Alkanethiolate-protected copper nanoparticles: Spectroscopy, electrochemistry, and solid-state morphological evolution. J Phys Chem B 105: 8816-8820.

60. Valodkar M, Jadeja RN, Thounaojam MC, Devkar RV, Thakore S (2011) Biocompatible synthesis of peptide capped copper nanoparticles and their biological effect on tumor cells. Mater Chem Phys 128: 83-89.

61. Lee HJ, Song JY, Kim BS (2013) Biological synthesis of copper nanoparticles using Magnolia kobus leaf extract and their antibacterial activity. J Chem Technol Biotechnol 88: 1971-1977.

62. Kulkarni VD, Kulkarni PS (2013) Green synthesis of copper nanoparticles using Ocimum sanctum leaf extract. Int J Chem Stud 1: 1-4.

63. Subhankari I, Nayak PL (2013) Synthesis of copper nanoparticles using Syzygium aromaticum (Cloves) aqueous extract by using green chemistry. World J Nano Sci Technol 2: 14-17.

64. Greenfield NJ (2006) Using circular dichroism collected as a function of temperature to determine the thermodynamics of protein unfolding and binding interactions. Nat Protoc 1: 2527-2535.
65. Rawel HM, Frey SK, Meidtner K, Kroll J, Schweigert FJ (2006) Determining the binding affinities of phenolic compounds to proteins by quenching of the intrinsic tryptophan fluorescence. Mol Nutr Food Res 50: 705-713.

66. Ramasubbu N, Ragunath C, Mishra PJ, Thomas LM, Gyémánt G, et al. (2004) Human salivary alpha-amylase $\operatorname{Trp} 58$ situated at subsite -2 is critical for enzyme activity. Eur J Biochem 271: 2517-2529.

67. Yoshikawa Y, Hirata R, Yasui H, Sakurai H (2009) Alpha-glucosidase inhibitory effect of anti-diabetic metal ions and their complexes. Biochimie 91: 1339-1341.

68. Vanco J, Marek J, Trávnícek Z, Racanská E, Muselík J, et al. (2008) Synthesis, structural characterization, antiradical and antidiabetic activities of copper(II) and zinc(II) Schiff base complexes derived from salicylaldehyde and ß-alanine. $\mathrm{J}$ Inorg Biochem 102: 595-605.

69. Yasumatsu N, Yoshikawa Y, Adachi Y, Sakurai H (2007) Antidiabetic copper(II)-picolinate: impact of the first transition metal in the metallopicolinate complexes. Bioorg Med Chem 15: 4917-4922.

70. Jiao Z, Liu J, Wang S (2005) Antioxidant activities of total pigment extract from blackberries. Food Technol Biotechnol 43: 97-102.

71. Hunt JV, Dean RT, Wolff SP (1988) Hydroxyl radical production and autoxidative glycosylation. Glucose autoxidation as the cause of protein damage in the experimental glycation model of diabetes mellitus and ageing. Biochem $\mathrm{J} 256$ : 205-212.

72. Wang Y, Xiang L, Wang C, Tang C, He X (2013) Antidiabetic and antioxidant effects and phytochemicals of mulberry fruit (Morus alba L.) polyphenol enhanced extract. PLoS One 8: e71144.

73. Tripathi YB, Singh VP (1996) Role of Tamra bhasma, an Ayurvedic preparation in the management of lipid peroxidation in liver of albino rats. Indian J Exp Biol 34: 66-70.

74. Sanyal AK, Pandey BL, Goel RK (1982) The effect of a traditional preparation of copper, tamrabhasma, on experimental ulcers and gastric secretion. J Ethnopharmacol 5: 79-89.

75. Patil S, Kanase A, Varute AT (1989) Effect of hepatoprotective ayurvedic drugs on lipases following $\mathrm{CCl} 4$ induced hepatic injury in rats. Indian J Exp Biol 27 955-958.

76. Rakhmetova AA, Alekseeva TP, Bogoslovskaya OA, Leipunskii IO, Ol'khovskaya IP, et al. (2010) Wound-healing properties of copper nanoparticles as a function of physicochemical parameters. Nanotechnologies Russ 5: 271-276.

77. McMurry JF Jr (1984) Wound healing with diabetes mellitus. Better glucose control for better wound healing in diabetes. Surg Clin North Am 64: 769-778.

78. Rafique S, Idrees M, Nasim A, Akbar H, Athar A (2010) Transition metal complexes as potential therapeutic agents. Biotechnol Mol Biol Rev 5: 38-45.

79. Rahimi R, Nikfar S, Larijani B, Abdollahi M (2005) A review on the role of antioxidants in the management of diabetes and its complications. Biomed Pharmacother 59: 365-373. 